\title{
Environmentalism among Norwegian Youth: Different Paths to Attitudes and Action?
}

Published in Journal of Youth Studies,(2000) Vol. 3, No. 2, :189-209

Ketil Skogen, Norwegian Social Research, NOVA ketil.skogen@nina.no

Åse Strandbu, Norwegian Social Research, NOVA ase.strandbu@nova.no

Department of Sociology and Human Geography University of Oslo

P.O.Box 1096 Blindern

N-0317 OSLO Norway

Telephone: $\quad+4722855257$

Fax: $\quad+4722855253$

Internet: http://www.iss.uio.no 
Journal of Youth Studies, Vol. 3, No. 2, pp. 189-209, 2000

\section{Environmentalism among Norwegian Youth: Different Paths to Attitudes and Action?}

\section{ÅSE STRANDBU \& KETIL SKOGEN}

ABSTRACT Based on a survey of three cohorts of youth in Oslo, aged 14-16 $(N=11425)$, the relevance of gender, class, cultural capital and political orientation to developing a pro-environmental orientation and joining an environmental organization was analysed. Cultural capital appeared to be of importance for developing strong environmental concern as well as for joining an environmental organization, while traditional measures of class background were less relevant. As many boys as girls were strongly concerned about the environment, but the majority of members of organizations were girls. The relationship between a conservative political orientation and strong environmental concern was positive, while the relationship between this political orientation and membership in an environmental organization was negative. Environmental issues now appear to have entered a realm of self-evident 'good things', regardless of political perspective. However, the more comprehensive critical stance found in most environmental organizations is still related to a radical political perspective.

\section{Introduction}

Several Norwegian studies have concluded that young people regard environmental issues as being among the most important societal problems [1] (Hegna, 1996; Skogen, 1996a; Strandbu, 1997). However, environmental youth organizations in Norway have lost members during the 1990s, as is the case in many other European countries. This probably indicates that the processes leading to involvement in the environmental movement are substantially different from the processes leading to environmental concern. A comparison of the two phenomena, which will be carried out in the present paper, can shed light on background factors influencing different forms of environmental concern among youth.

\section{Environmental Concern and Participation in the Environmental Movement}

The social conditions for development of pro-environmental orientations have preoccupied many social researchers. Among others, Graumann \& Kruse (1990) have argued that each society constructs its view of nature and environmental problems in accordance with its cultural values and social and political forces. Others have highlighted the substantial disparity in environmental awareness in the same society. Mary Douglas, in her 'cultural theory of risk', has tried to explain the variation in patterns of perceived risk-where the perception of 
environmental problems is a major example. Her argument is that people's perception of the environmental situation reflects their cosmology-their underlying assumptions and values about order, hierarchy, and the just society (Douglas \& Wildavsky, 1983; Douglas, 1992).

Differences in pro-environmental attitudes and pro-environmental actions have been the subject of many studies (Axelrod \& Lehman, 1993; Scott \& Willitts, 1994; Steel, 1996; Stern et al., 1995; Szagun \& Pavlov, 1995; Wall, 1995). A common way to deal with these questions has been to investigate the difference between attitudes and self-reported willingness to take part in pro-environmental action. Another approach to different levels of involvement is to investigate different routes to pro-environmental attitudes and membership in environmental organizations. This will be done in the present paper.

One environmental organization is completely dominant among young people in Norway. This is 'Nature and Youth' (Natur og Ungdom, NU), the youth organization of the Norwegian Society for Conservation of Nature (Norges Naturvernforbund, NNV). NU is more radical than its parent organization, and comparatively independent of it. NU has frequently resorted to forms of direct action of which NNV does not approve [2], and emphasizes the necessity of understanding environmental problems in a global and political context. However, NU also works locally with a wide range of more specific issues. In this study, we will consider membership of NU as an appropriate indicator of affiliation with pro-environmental action. For most of the members, participation in NU indicates a willingness to work for the goals of the organization. Quite a few members are even prepared to take part in illegal protest actions and to risk penal reactions.

What is perceived as lack of interest in politics and limited participation in political processes among young people has been addressed by many political commentators. Young people's lack of involvement in party politics has been explained as apathy, cynicism and lack of knowledge (cf. Øia, 1995; Furlong \& Cartmel, 1997). Shortcomings in political socialization have also been suggested (Aardal, 1993). One way to understand young people's political engagement better is to study those who take part in different forms of political work. Who are they? In this paper the differences between members of an environmental organization and non-members with a strong environmental concern will be discussed. Background characteristics such as gender, class, cultural capital, cultural preference and political orientation will be considered.

\section{Class and Cultural Capital}

Environmental orientations probably develop in much the same way as most other forms of (political) socialization, with parents, friends, school, workmates and media as important socializing agents. According to Furlong \& Cartmel (1997), the effects of parental influence on which political party children support have weakened since the 1960s, but after a review of British studies their conclusion was that parental influence still has a significant effect on political socialization. In this paper, parents' influence on political socialization is discussed in terms of class background and the cultural climate in the home.

Why could we expect class background to be relevant to environmental orientation? Some studies have shown differences in environmental orientation between people in occupations related to the use of natural resources and people 
in other types of occupation. The former group has a more practical attitude and is less concerned with environmental consequences (Kowalevski, 1994). The distinction between practical and symbolic orientation towards nature has a broader relevance. In other studies a distinction between abstraction- and production-oriented cultures originating from different class positions has been proposed to explain different attitudes towards nature and environmental problems (Skogen, 1996b). The abstraction-oriented culture acclaims flexibility and strategic thinking and is developed in the sectors of society where symbols and not material objects are manipulated. In the production-oriented culture, practical sense is preferred to remote speculations, and theory is only legitimate in so far as it is a generalization of practical experience. Practical use of nature and a feeling of affinity towards concrete activities in nature are assumed to be most typical of the production-oriented culture. Aesthetic fascination and philosophical reflections on nature are more characteristic of the abstraction-oriented culture. The abstraction-oriented culture is therefore suggested to be intrinsic to the middle-class-based environmental movement (Skogen, 1996b).

Numerous studies have shown that highly educated groups, especially in the 'non-productive' sectors of the economy (public services, teaching, etc.), feel a relatively strong affinity to the environmental movement and regard environmental problems as important (Eckersley, 1989; Kriesi, 1989). A 1992 survey demonstrated that young people with a background in the humanistic-social fraction of the middle class had stronger pro-environmental attitudes and were over-represented in environmental organizations (Skogen, 1996b). It is interesting to investigate whether this is still the case, or if we are indeed witnessing an accelerating impairment of class cultures as proposed by commentators such as Giddens (1991) and Beck (1992). The dominance of particular middle-class segments also highlights the need for a concept of class that takes more than economic location into consideration, and we propose to focus on the salience of cultural orientations and cultural domination.

In this connection we will draw upon Bourdieu's contribution to the theory of symbolic power. Bourdieu uses the term symbolic capital to describe how certain people or institutions, certain forms of knowledge, and certain value orientations are ascribed respectability and prestige and command deference. Further, in this respect the concept of cultural capital encompasses familiarity with and access to the legitimate and dominating culture. Cultural capital is an 'inherited' social competence that is unequally distributed in the class structure.

We ask whether notions of nature are subject to cultural and social domination. Another aim of this study is to explore whether measures of cultural capital give more complete information on the origins of environmental concern than a more traditional conceptualization of class, focusing on the occupational structure.

\section{Gender}

Another important subject in this study is the significance of gender. Earlier studies have revealed gender differences in attitudes towards the environment and in environmental political activism (Mohai, 1992). For example, Davidson \& Freudenburg (1996), in a review article of American studies, concluded that women tended to express higher levels of concern about potential environmental 
and technological crises than men [3]. This gender difference has also been found in studies of younger cohorts (Skogen, 1996b).

Gender differences can be explained, according to some feminist researchers, by different value orientations, which are also expressed in different political priorities (Shapiro \& Majahan, 1986). Value research has found women to be more collectively oriented and less individualistic than men. Women also seem to be more oriented towards equality and more concerned about environmental problems (Listhaug \& Huseby, 1995). Women's 'softer' value orientation has not traditionally resulted in political involvement. Many studies have shown that even when women express a stronger concern for the environment than men, they are less politically active in relation to these issues (Mitchell, 1979; McStay \& Dunlap, 1983; Mohai, 1992). As few studies have focused on young people, there is a need to probe into whether the gender gap in environmental concern and activism also exists among the younger generations.

\section{Political Orientation}

A common assumption is that environmental concern is part of a leftist political orientation. This seems especially apparent regarding the critical stance towards economic growth and industrial capitalism found within the ecological movement. On the other hand, conservationist environmental organizations have historically been situated on the right of the political spectrum; a shift to the political left occurred with the transformation of environmentalism into a modern ecological discourse (Eder, 1996, p. 178).

To some degree, the leftist link to environmental concern is confirmed in studies of political attitudes. Analyses of party programmes (Bjørklund \& Hellevik, 1988) and analyses of voters' environmental orientation in Norway (Seippel, 1995) have broadly corroborated this picture. In Norway, the left socialist party and the liberal party give high priority to environmental issues, while the two conservative parties are the least environmentally oriented. However, according to some young spokespersons of the conservative party, environmental concern could just as well be seen as part of a conservative ideology. 'What is more conservative than caring for the environment?' was a slogan proposed by two young members of the conservative party in Aftenposten (the leading Norwegian conservative newspaper) on 9 July 1998.

Does such environmental concern also exist among other youth groups with a right-leaning political sympathy? Or is environmental concern among youth predominantly a leftist orientation? Earlier research has found some pro-environmental attitudes [4] and the joining of an environmental organization to be related to a youth cultural orientation labelled radical counterculture (Skogen, 1996b). In the present paper we will look at environmental concern related to measures of political orientation. We want to find out whether environmental concern is still part of a leftist orientation, or whether such concern has become integrated in mainstream politics.

\section{Research Questions}

The present paper focuses on the following issues: 
- What is the relevance of gender, class, cultural capital and political orientation in the development of pro-environmental orientations, and in the joining of an environmental organization?

- Are there differences between those with pro-environmental orientations who are members of an environmental organization and those with proenvironmental orientations who are not members? What can such differences tell us about processes leading to participation in environmental organizations?

\section{Method}

\section{Sample}

The data stem from a 1996 survey of young people in Oslo. The total population of the age cohorts born in 1982, 1983 and 1984 was included. This includes the two final years in compulsory lower secondary school and the first year in upper secondary school. In Norway $98.5 \%$ of adolescents between 12 and 15 years attend lower secondary school. Upper secondary school is not compulsory, but about $95 \%$ of those leaving the lower secondary school attend upper secondary school the next autumn. Eleven thousand four hundred and fifty respondents, $94.3 \%$ of the population, answered the questionnaire. The non-response of nearly $6 \%$ was due to either unwillingness to participate or prolonged absence from school. The data collection was administered by the schools in cooperation with Norwegian Social Research (NOVA), and the questionnaires were completed in school.

The survey was used to investigate a wide range of issues. The weakness of the data set for our purpose is that it contains only a few measures of environmental attitudes and action.

Some respondents did not answer all the questions. For example, about $8 \%$ did not get as far as the questions about participation in organizations, which were on the last page. Young people with an immigrant background were over-represented in this group. However, due to the high response rate we were still able to address our research questions.

\section{Measures}

First, the respondents were asked if they were members of an environmental organization. Then, environmental orientation was measured according to degree of support for 16 statements about 'possible goals for the nation'. The respondents were asked to give from one to 10 points to each of the statements, depending on the importance they assigned to them. Three of the statements were pertinent to environmental issues: 'protect the environment against pollution', 'protect untouched Norwegian nature against all harmful resource extraction' and 'provide total protection to the large carnivores, even if they kill domestic animals'.

The class variable was constructed by categorizing parents' occupations according to the ISCO-88 system (International Labour Organization, 1990). Fathers' occupation was primarily used as a basis for classification. Mothers' occupation was used when information on fathers was lacking. A sixfold classification was adopted, developed by Skogen (1996a, b, 1998): professional leaders, technical-economic intermediate strata, humanistic-social intermediate 
strata, clerical workers, manual workers, and unemployed or on social security benefits. Examples of occupations placed in the technical-economic intermediate strata are engineers and economists, whereas occupations such as teachers, doctors and social workers were placed in the humanistic-social intermediate strata. The argument for using primarily fathers' occupation to determine class locations is that fathers more often work full time than mothers, and that fathers' class location is still probably most significant for what we might term the 'class cultural climate' in the family.

Cultural capital was measured in several ways. The respondents were asked how many books there were in their home (six options from 'none' to 'over $\left.1000^{\prime}\right)$. Media consumption was another indicator. Previous research has shown that media consumption is related to social class and lifestyle (for a review, see Rosengren, 1994). Media habits could be considered as indicators of cultural capital-and they could also be considered to play a part in the reproduction of world-view and political values (Pedersen, 1996). The television situation in Norway changed towards the end of the 1980s. The broadcasting monopoly held by the state channel NRK was brought to an end and commercial channels invaded the scene. National media research has concluded that the commercial channels are less popular among the highly educated. The opposite holds for the state channel (Vaage, 1997). In the present study, the respondents were asked which of eight different programmes they themselves, their father and their mother would like to watch-some from the three large commercial channels and some rather 'intellectual' programmes from NRK. Media consumption and the number of books in the home are of course a narrow operational definition of cultural capital, but have been found to be useful indicators in other studies (Pedersen, 1996).

Number of books in the home and parents' TV preferences measure the family's cultural capital. The respondents' own TV preferences were meant to indicate the respondents' cultural capital, in so far as this diverged from that of the family.

The statements about 'possible goals for the nation' were intended to measure political orientation. Three of the statements: 'ensure continued economic growth', 'ensure a strong defence' and 'reduce public involvement in private life' were selected to measure a conservative political orientation. Unfortunately, a good measure of political radicalism was difficult to construct on the basis of the given items. We therefore considered a low score on the conservative dimension as a crude indicator of a radical orientation.

\section{Results}

\section{Environmental Orientation}

As Table 1 shows, pro-environmental attitudes were strong in the general youth population. Preventing unemployment [5] was the only goal which was given higher priority than protecting the environment against pollution [6]. More surprising than the concern about pollution was the desire to protect untouched nature. This was the third most important issue according to the respondents. Concern for protecting the carnivores was not so strong, but was still regarded as more important than five of the other 16 statements.

In the further analysis, a sum score variable was used. It was constructed as the mean score on the three items relating to environmental issues. There was 
Table 1. Support for different goals for the nation. Scale from 1 to 10 . Ranked means

\begin{tabular}{|c|c|c|c|c|c|}
\hline & Total & Boys & Girls & $\mathrm{F}$ & Significance \\
\hline Provides work for everyone & 8.6 & 8.3 & 8.9 & 169.8 & $* * *$ \\
\hline Protect the environment against pollution & 8.3 & 8.1 & 8.6 & 168.7 & $* * *$ \\
\hline $\begin{array}{l}\text { Protect untouched Norwegian nature } \\
\text { against harmful resource extraction and } \\
\text { development }\end{array}$ & 7.9 & 7.6 & 8.1 & 74.7 & **** \\
\hline Maintain law and order & 7.9 & 7.7 & 8.0 & 52.1 & *** \\
\hline $\begin{array}{l}\text { Give people more influence at work and in } \\
\text { their neighbourhoods }\end{array}$ & 7.1 & 6.9 & 7.3 & 70.9 & $* * *$ \\
\hline $\begin{array}{l}\text { Provide people with a safe and dignified } \\
\text { old age, even if young people have to } \\
\text { pay for it }\end{array}$ & 7.0 & 6.7 & 7.3 & 146.1 & $* * *$ \\
\hline Provide continued economic growth & 6.7 & 6.9 & 6.4 & 96.4 & $* * *$ \\
\hline $\begin{array}{l}\text { Promote Norwegian success in } \\
\text { international sports }\end{array}$ & 6.5 & 6.9 & 6.1 & 160.2 & $* * *$ \\
\hline Provide a strong defence & 6.4 & 6.5 & 6.3 & 13.1 & *** \\
\hline $\begin{array}{l}\text { Give people more influence in important } \\
\text { political decisions }\end{array}$ & 6.3 & 6.2 & 6.5 & 18.4 & *** \\
\hline $\begin{array}{l}\text { Provide protection to the large carnivores, } \\
\text { even if they kill domestic animals }\end{array}$ & 6.3 & 6.6 & 6.0 & 82.2 & $* * *$ \\
\hline $\begin{array}{l}\text { Keep Norway free and independent of } \\
\text { international influence }\end{array}$ & 5.8 & 5.9 & 5.8 & 5.3 & * \\
\hline Reduce public involvement in private life & 5.6 & 5.7 & 5.5 & 12.3 & *** \\
\hline $\begin{array}{l}\text { Make Norway admit more refugees and } \\
\text { asylum seekers }\end{array}$ & 5.4 & 4.9 & 5.8 & 216.8 & $* * *$ \\
\hline $\begin{array}{l}\text { Protect Norwegian culture and language } \\
\text { against Anglo-American influence }\end{array}$ & 3.9 & 4.0 & 3.8 & 12.2 & $* * *$ \\
\hline Prevent the mixing of races & 3.9 & 4.2 & 3.5 & 80.9 & $* * *$ \\
\hline$N$ & $8226-9253$ & $4290-4652$ & $3902-4617$ & & \\
\hline
\end{tabular}

Note: $7.2 \%$ did not answer the extended version of the questionnaire which contained these questions. $* * *=p<0.001 ; *=p<0.01$.

quite a high correlation between support for fighting pollution and protecting the wilderness $(r=0.54)$, and a weaker correlation between concern for the carnivores and the other two measures $(r=0.29$ and 0.33 respectively). Reliability analysis showed an increase in Kronbach's alpha from 0.63 to 0.70 if the carnivores were removed from the variable. The argument for keeping them is that we wanted a sum score variable consisting of different items concerning the environment. To treat the three goals of environmental orientation as indicators in an index is an oversimplification (Skogen, 1998, 1999), but we consider this to be acceptable for the purpose of this paper, where the focus was on differences between passive and active environmental concern.

Generally, the results pointed in the same direction as earlier research: girls were more concerned than boys (mean scores 7.61 versus 7.43), and youth from the upper and middle classes scored higher on environmental orientation than youth from a 'lower' class background. We also found preoccupation with environmental issues to be associated with amount of cultural capital. The more books at home, the more predominant were pro-environmental attitudes.

Exploratory factor analysis (Varimax rotation) was carried out on the TV preference variables, and a relatively uniform factor solution was found for both 
the respondents' and their mothers' and fathers' TV habits [7]. The first factor was dominated by entertainment programmes from the commercial channels and was labelled commercial. The second comprised the more serious programmes (mainly about cultural and political issues) from the state channel and was labelled intellectual. The initial factor solution for respondents' and fathers' TV preferences had another third factor consisting of preference for two of the commercial programmes. However, this third factor had a low eigenvalue (1.06) and reliability analysis showed a higher Kronbach's alpha for the sum score variable if these two programmes were included in the first commercial dimension. We therefore treated the commercial programmes as one dimension. Both the intellectual and the commercial dimensions were related to environmental orientation. Using another sample, but similar programmes, Pedersen (1996) found a four-factor solution. The two dimensions that were useful for his discussion of ethnic prejudice were rather similar to the two that emerged here-intellectual TV and commercial TV.

Mothers' and fathers' TV preferences were highly correlated (interest for commercial TV: $r=0.64$; interest for intellectual TV: $r=0.59$ ). Both mother's and father's TV preferences were of importance for the youth's environmental orientation, so for the further analysis we constructed a sum score variable including both parents' TV preferences. If mother and father preferred intellectual TV, then the probability of their offspring having pro-environmental attitudes was strong. The opposite held for interest in commercial TV. The offspring's interest in commercial TV had no clear relationship to environmental orientation, but preferences for intellectual TV were associated with high support for fighting pollution and protecting untouched nature.

The statistical effects of background factors such as class and gender on environmental orientation were rather weak. The main impression was that environmental issues were important for most young people and that the impact of social background was not very strong (see Table 2).

Political orientation was more relevant for environmental concern. A sum score variable for a conservative political orientation was constructed based on questions about three goals for the nation: 'ensure continued economic growth', 'ensure a strong defence' and 'reduce public involvement in private life'. These goals represent core values in the conservative and economically liberal ideology of most conservative parties. A conservative political orientation was, rather surprisingly, found to have a distinct positive association with environmental concern. As mentioned earlier, a low score on conservative orientation was considered to be a crude indicator of a radical orientation. By way of this measure, radicalism was not found to be associated with environmental concern.

In order to investigate the unique effects of gender, class, parental cultural capital and the respondents' cultural capital on having a strong environmental concern, three logistic regressions were carried out. By strong environmental concern we mean giving nine or more points on average to the three environmental issues. The explanatory variables were introduced in three blocks. (See Table 3.)

Dummy variables were used for class locations. Gender and father's social class were introduced in block 1 . No significant effect was found for gender. Background in the humanistic-social fraction of the middle class had a significant positive effect. The other classes were not significantly different from the reference category (manual workers). 
Table 2. Environmental concern, mean scores

\begin{tabular}{|c|c|c|c|c|c|}
\hline & & Mean & $N$ & $\mathrm{~F}$ & Significance \\
\hline Gender & Boys & 7.43 & 4632 & 18.73 & $* * *$ \\
\hline Girls & 7.61 & 4590 & & & \\
\hline Total & 7.52 & 9222 & & & \\
\hline \multirow[t]{7}{*}{ Class } & Professional leaders & 7.64 & 868 & 11.06 & $* * *$ \\
\hline & $\begin{array}{l}\text { Technical/economic } \\
\text { middle class }\end{array}$ & 7.63 & 2949 & & \\
\hline & $\begin{array}{l}\text { Humanistic/social } \\
\text { middle class }\end{array}$ & 7.71 & 1816 & & \\
\hline & Clerical workers & 7.45 & 954 & & \\
\hline & Manual workers & 7.37 & 2077 & & \\
\hline & $\begin{array}{l}\text { Unemployed/on } \\
\text { social security }\end{array}$ & 7.07 & 216 & & \\
\hline & Total & 7.55 & 8880 & & \\
\hline \multirow[t]{6}{*}{ Books at home } & Less than 20 & 6.73 & 414 & 40.35 & $* * *$ \\
\hline & $20-100$ & 7.20 & 1538 & & \\
\hline & $100-500$ & 7.52 & 3048 & & \\
\hline & $500-1000$ & 7.69 & 2651 & & \\
\hline & More than 1000 & 7.77 & 1554 & & \\
\hline & Total & 7.52 & 9205 & & \\
\hline \multirow{3}{*}{$\begin{array}{l}\text { Parents- } \\
\text { intellectual TV }\end{array}$} & Do not like & 7.37 & 4091 & 50.02 & $* * *$ \\
\hline & Like & 7.66 & 4727 & & \\
\hline & Total & 7.52 & 8818 & & \\
\hline \multirow{3}{*}{$\begin{array}{l}\text { Parents- } \\
\text { commercial TV }\end{array}$} & Do not like & 7.63 & 5346 & 36.26 & $* * *$ \\
\hline & Like & 7.39 & 3773 & & \\
\hline & Total & 7.53 & 9119 & & \\
\hline \multirow{3}{*}{$\begin{array}{l}\text { Respondent- } \\
\text { intellectual TV }\end{array}$} & Do not like & 7.49 & 7994 & 31.92 & $* * *$ \\
\hline & Like & 7.87 & 889 & & \\
\hline & Total & 7.53 & 8883 & & \\
\hline \multirow{3}{*}{$\begin{array}{l}\text { Respondent- } \\
\text { commercial TV }\end{array}$} & Do not like & 7.54 & 5940 & 0.59 & n.s. \\
\hline & Like & 7.51 & 3226 & & \\
\hline & Total & 7.53 & 9166 & & \\
\hline \multirow{4}{*}{$\begin{array}{l}\text { Conservative } \\
\text { orientation }\end{array}$} & Low & 6.74 & 2473 & 335.54 & $* * *$ \\
\hline & Average & 7.71 & 5864 & & \\
\hline & High & 8.39 & 885 & & \\
\hline & Total & 7.51 & 9222 & & \\
\hline
\end{tabular}

${ }^{* * *}=p<0.001 ; * *=p<0.01 ; *=p<0.05$.

In block 2, indicators of cultural capital in the home were introduced. Many books at home increased the respondents' probability of having a strong environmental concern, while parents' preferences for commercial TV decreased the probability. The effect of background in the humanistic-social middle-class fraction was weakened. This is not surprising, since possessing a high amount of cultural capital is characteristic for this class fraction. Thus, family background appears to be relevant for having a strong environmental concern, although class background alone does not account for much of the variation. The indicators of cultural capital in the home were more powerful.

Indicators of the respondents' cultural capital and their political orientation 
198 Å. Strandbu \& K. Skogen

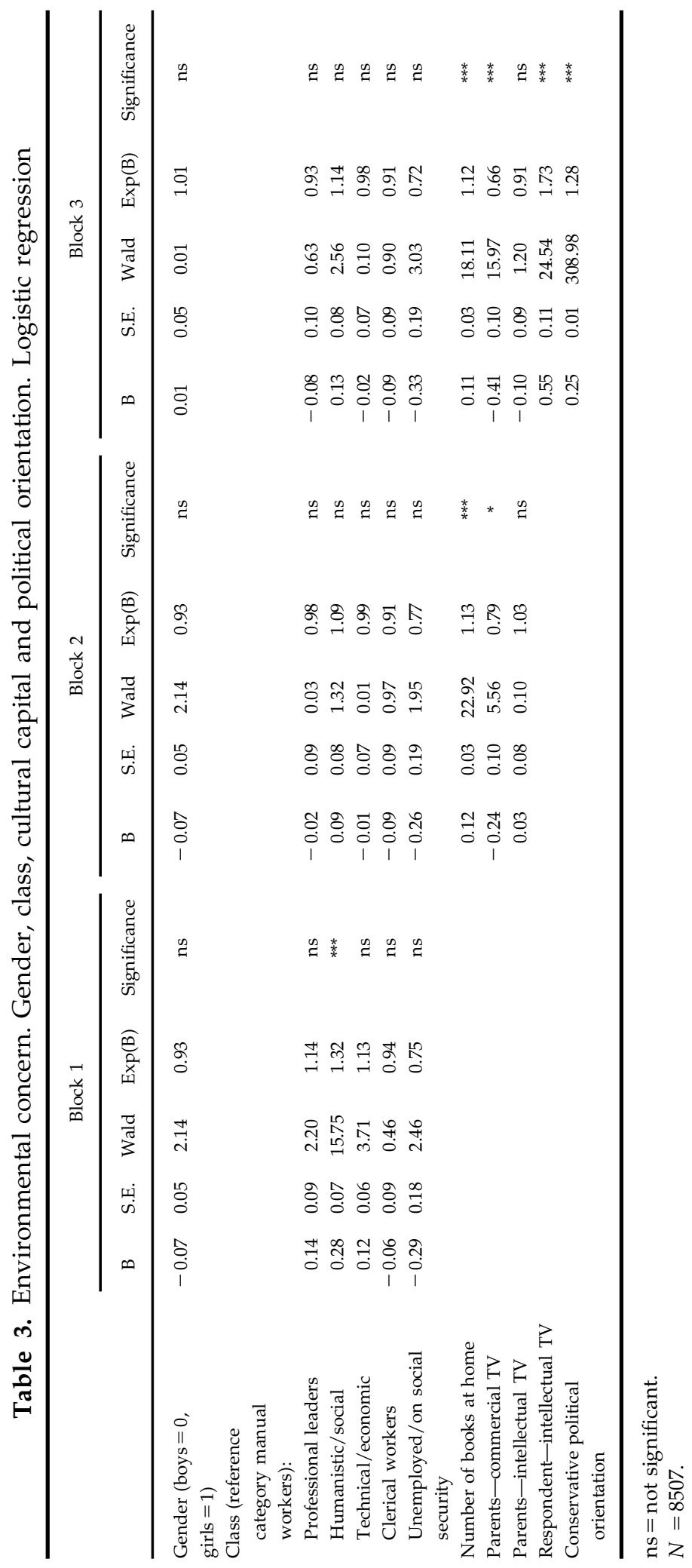


were introduced in block 3 . The respondents' interest in watching intellectual programmes had a significant positive effect towards a strong environmental concern. A conservative political orientation also increased the probability of having a strong environmental concern.

\section{From Pro-environmental Orientation to Becoming a Member of an Environmental Organization}

Two point one per cent of the respondents were members of an environmental organization $(2.8 \%$ of the girls and $1.5 \%$ of the boys); $2.6 \%$ of the oldest age cohort were members, and $1.5 \%$ of the youngest [8]. In order to obtain a picture of what makes the difference between having a pro-environmental orientation and joining an organization, we will compare two groups: those with pro-environmental orientations who were members of an environmental organization and those with pro-environmental orientations who were not members of such organizations.

To this end a new variable, environmental concern, was constructed. The respondents' were grouped into three categories. Those who gave less than nine points to the sum score variable measuring environmental attitudes were said to have a weak or average environmental concern. Those who gave nine points or more, but were not members of an environmental organization, were classified as having a 'strong but passive' environmental concern. Finally, those who were members of an environmental organization were classified as having a 'strong and active' environmental concern. Comparison of the last two groups is of greatest interest here. (See Table 4.)

When we compared these two groups some clear tendencies emerged. Girls were over-represented among the organization members. So were youth from the humanistic-social fraction of the middle class, while working-class youth were under-represented. The amount of cultural capital was higher among the members: there were more books in their homes, their parents were more apt to like intellectual TV and were less interested in commercial TV. Among the members a larger proportion was interested in intellectual TV than in the other groups. Support for conservative political values was less among members than among those with a strong, but passive, environmental concern.

Logistic regression was applied in order to investigate the unique effects of gender, class, parental cultural capital and the respondent's cultural capital and political orientation upon the propensity to join an environmental organization. Only those with a strong environmental concern were selected for these analyses $(N=2608)$. The variables were introduced in blocks. (See Table 5.)

In block 1, organization membership was predicted on the basis of gender and father's social class. A significant effect of gender was found, in that girls were more likely to join an organization. A background from the humanistic-social fraction of the middle class also had a positive effect. The other classes were not significantly different from the reference category (manual workers).

In block 2 indicators of cultural capital in the home were introduced. Number of books and parents' preferences for intellectual TV had a positive effect. The effect of commercial TV preferences was negative. As in the former regression, the effect of background in the humanistic-social middle-class fraction was weakened. Again, this is not surprising given the centrality of cultural capital to this class fraction. 
Table 4. Comparison of groups according to environmental concern

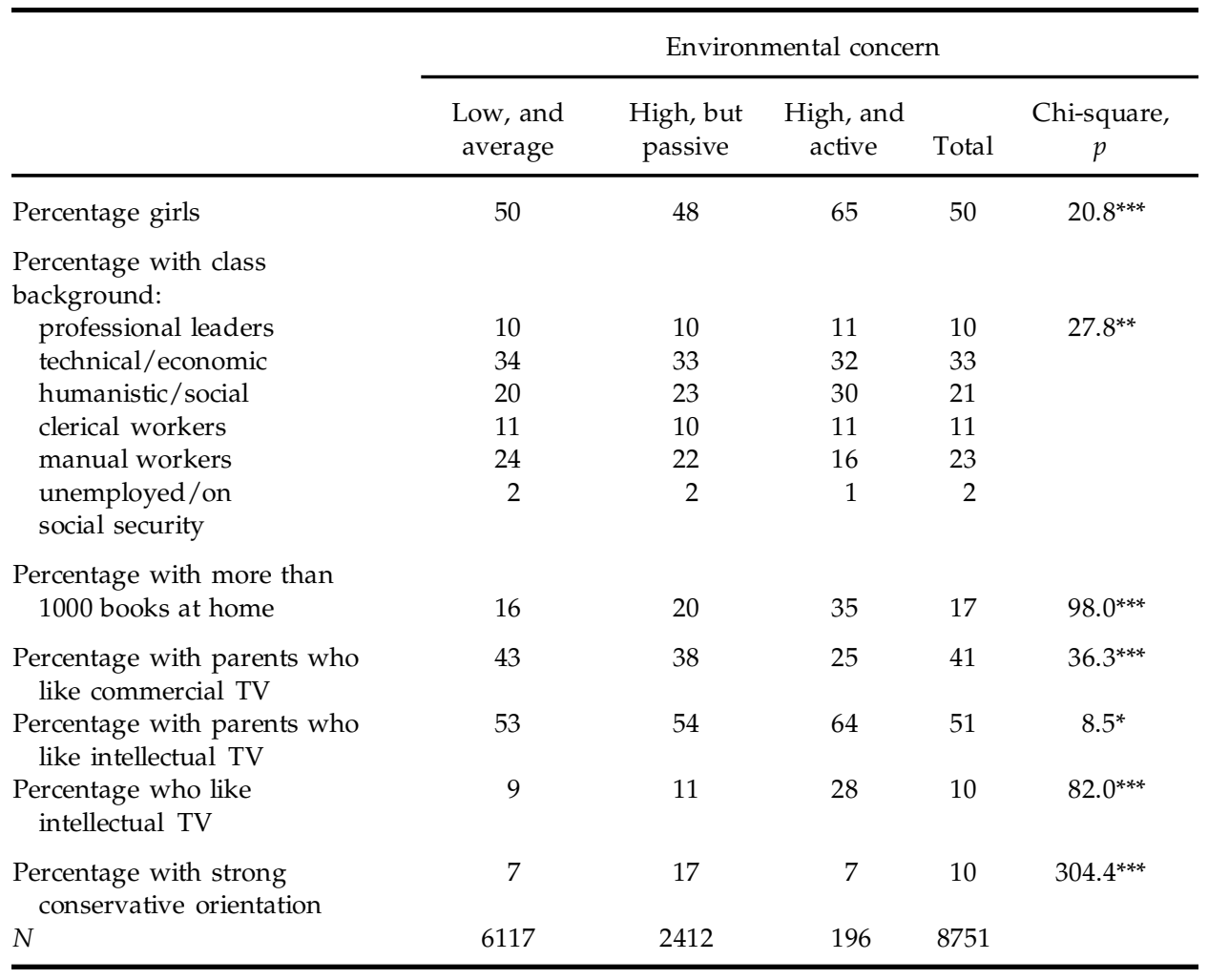

${ }^{* * *}=p<0.001 ; * *=p<0.01 ; *=p<0.05$.

When entering block 3 , we found that the respondents' interest in watching intellectual programmes had a positive effect on the likelihood of becoming a member of an environmental organization. The effects of parents' TV preferences were weakened when the respondents' own preferences were introduced. Number of books at home still held its position. It seems reasonable to assume that the influence of the family's cultural capital was partly mediated through the respondents' own media preferences. However, the family's cultural capital still had a separate effect on the likelihood of becoming a member of an environmental organization. A conservative political orientation decreased the likelihood of joining.

\section{Discussion}

\section{Cultural Capital and Class}

Measures of fathers' class were not found to be of much significance for environmental concern. Cultural capital seemed to be important for developing a strong environmental concern, as well as for joining an environmental organization. Having many books at home and preferences for intellectual TV had the 
Environmentalism among Norwegian Youth 201

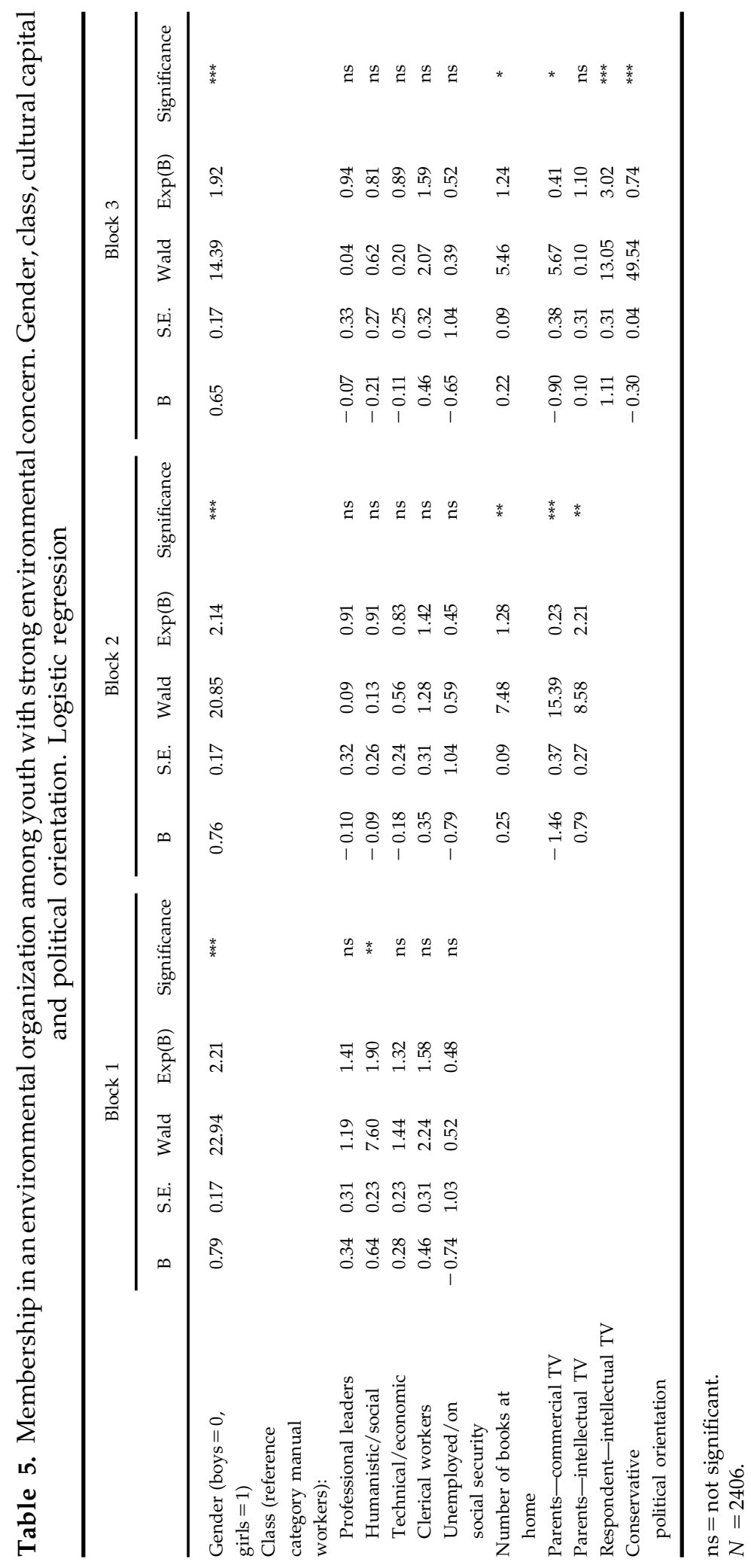


same effect. When we take cultural capital into account, together with class background, the effect of cultural capital still holds, but not that of class.

There might be several reasons why cultural capital is more important than class background for the development of young people's environmental orientation. A methodological point is that a measure of class based on father's class location is an oversimplification. Father's class location is probably in general the most salient factor for locating a family in the class structure. However, when it comes to value orientations, the mother may be the most important socialization agent. A German study concluded that most young people talk more about politics with their father than with their mother. Even so, the impact of mother's opinions on those of the children was generally the strongest (Weiss et al., 1998). In line with this, mother's class location could be an important modifying factor. The measures of cultural capital employed here in a sense represent, even if they are oversimplifications, a summary of mother's and father's cultural capital, and could be more appropriate for that reason.

Do these results support the suggestion that we are witnessing a dissolution of class cultures, as suggested for example by Giddens (1991) and Beck (1992)? Our data are of course much too limited to draw a strong conclusion on this issue. However, the findings suggest that traditional varieties of class analysis that do not take cultural diversity into consideration are less useful for understanding environmental attitudes and environmental action. The background factors that seem relevant here are those which reflect cultural diversity. As we are dealing with young people in 'mediated class locations' (Wright, 1997), the impact of cultural capital, as well as that of class (however limited), clearly indicates a cultural continuity across generations. Such continuity could partly be understood as a result of internalization of the parent culture in childhood, and partly as a result of shared living conditions between age groups. But, granted that we have established cultural continuity, why is cultural capital relevant in the first place? Why does cultural capital induce pro-environmental attitudes and environmental organization membership? We will suggest two explanations, both relating to forms of cultural domination.

First, the weaker environmental concern among those with a limited amount of cultural capital could be explained with reference to the distinction between a production-oriented and an abstraction-oriented culture (Skogen, 1996b). Within the abstraction-oriented culture we expect to find an emphasis on aesthetic evaluation of nature, and a propensity toward identification with abstract totalities (such as our planet, all living things, etc.). Fascination with unspoiled, remote wilderness areas, concern for threatened animal species, and rejection of the crude materialism that leads to destructive exploitation of nature, are all elements that fit the abstraction-oriented culture.

The production-oriented culture embodies scepticism towards abstractions and towards people involved in intellectual work, and, conversely, a basal trust in down-to-earth practical sense. Abstract holism as promoted by the environmental movement will not fit well into the production-oriented culture, which is generally hostile to abstractions. Preoccupation with environmental problems might be associated with some sort of intellectualism and this may contribute to the expulsion groups that are low in cultural capital (cultural capital being closely tied to an abstraction-oriented culture). The complexity of many environmental problems (at least as they are construed by science, and subsequently by the media) demands substantial theoretical knowledge. This could be another 
reason why involvement in the environmental movement (indeed, concern for certain types of apparently abstract and distant environmental problems in general) corresponds to being well educated.

Because the abstraction-oriented culture is characteristic of the upper and middle classes, and because it penetrates all hegemonic institutions in modern society, it is a dominant culture in relation to the production-oriented culture which predominantly prevails in the working class. But symbolic domination is also relevant along a different axis. In the literature on social movements, the typical over-representation of the new middle classes is explained in the light of their position as relatively separated from the productive sector and the market, which again leads to characteristic value orientations (cf. Scott, 1990; Eder, 1993). Their relatively limited influence on important economic issues leads them to stress the importance of alternative values, such as ethics and aesthetics. They seem driven towards developing alternative (ideologically anti-materialist) conceptions of 'the good life' (Eder, 1993, p. 181), something which is also nicely suited to the value orientations and ideologies found within the environmental movement and other new social movements.

We roughly follow Bourdieu's (1984) thoughts about the relative values of economic and cultural capital, even if his focus is mainly on differentiation within the upper and middle classes. Our findings indicate that this line of reasoning might not only be relevant in relation to the middle class. When class background was controlled for, cultural capital was found to increase the probability for having a strong environmental concern and for joining an environmental organization. It seems reasonable to assume that a higher amount of cultural capital might, in all classes, induce some sort of alternative value orientation. If so, this will also apply to groups of workers with low incomes, but which are relatively well educated [9], and whose urge to develop alternative life orientations could be motivated by many of the same factors as within the well-educated, but economically side-tracked, fractions of the middle class. A feeling of being undervalued economically could be linked to a stronger support for alternative values, such as attitudes pro-environmental.

Our findings support the suggestion that knowledge of the environmental situation and a 'correct' perception of nature could be considered as cultural capital. The modern middle-class notions of nature (summarized in the term 'romantic gaze') which express a distinction towards the utilitarian relations to nature found among manual workers and farmers, and towards the unaesthetic consequences of industrialism, are one example (Eder, 1996; Macnaghten \& Urry, 1998). In line with recent contributions to the sociology of nature (Eder, 1996; Macnaghten \& Urry, 1998) we suggest that notions of nature are embedded in different forms of social life-and are subject to cultural and social domination as are any other cultural forms.

\section{Environmental Concern and Political Orientation}

The most surprising result was the positive association between a conservative political orientation and pro-environmental attitudes. How can we understand this? First some methodological reflections. Based on previous research, we would expect a leftist political orientation to go hand-in-hand with proenvironmental attitudes (cf. Skogen, 1999). However, the most popular statements about goals for the nation generally reflect 'responsible' mainstream 
issues and uncontroversial 'good things', and pro-environmental statements are now part of this realm. It appears that pro-environmental attitudes may be associated with various types of social or political engagement, and those who are not concerned about mainstream political issues are generally not interested in environmental issues either. In other words, pro-environmental attitudes have become part of a mainstream stock of political ideas. We can discern some of the same tendencies in contemporary political debate. In a recent controversy over the possible construction of new gas power plants in Norway (which would increase Norwegian $\mathrm{CO}_{2}$ emissions considerably), both opponents and proponents highlighted arguments about the environmental benefits. Those in favour of the new power plants claimed that electricity could be exported and could replace electricity generated at much-more-polluting coal power plants. Those who were against contended that Norwegian energy consumption is much to high, and that electricity from the new $\mathrm{CO}_{2}$-spewing plants is not really needed. Thus, environmental arguments were among the most legitimate in this debate. Another indicator of the political neutralization of environmental issues is the fact that alliances between business and environmental organizations are becoming increasingly common. Bellona [10], one of the most renowned groups of environmental activists in Norway, now cooperates with several industrial enterprises, and derives much of its funds from these sources. These activists have changed their physical appearance and way of dressing accordingly, from a rough 'activist' look with long hair and worn sweaters to a business style with suits and ties.

This political neutralization of environmental issues is probably particularly relevant for young people. The respondents in this survey grew up in the 1980s and 1990s when environmental issues received much attention both in the media and in other institutions of relevance for political socialization. Not least, the emphasis on environmental issues in school has been considerable in this period. Considering this, it may not be so surprising that pro-environmental attitudes also fit in with a conservative political orientation. Such attitudes are probably positively associated with political interest generally. If the measures of political radicalism had been more precise, the correlation with environmental concern would probably also have been high. It is most likely those who are not interested in politics who do not regard environmental issues as important. Pro-environmental orientation is connected to political interest as such, but (at least on the very general level measured in this survey) it is a politically neutral issue among youth.

However, recruitment to NU reveals another picture. Membership is negatively associated with a conservative political orientation. This means that we discern here the anticipated connection to a leftist political inclination. The distinction proposed by Arne Næss (1973) between shallow and deep ecology may be relevant here. According to Næss, a belief in solving environmental problems without fundamental changes in lifestyles and in our economic system is a shallow ecological approach. On the other hand, deep ecology implies a view of sustainable production and consumption which requires fundamental changes in our relationship to nature, and thus necessarily also major societal changes.

In its self-presentation NU claims to be part of the deep ecology movement, and the positions taken by this organization on many issues clearly reveal its politically radical ideological foundation. It seems reasonable that this particular type of environmental concern does not fit in with a conservative political 
orientation, where, for example, economic growth is generally seen as desirable. The latter can only be integrated into what Næss would call a shallow ecology. Nevertheless, it is perfectly possible to endorse both pro-environmental statements (like those in our questionnaire) and economic growth.

The different relevance of political orientation for pro-environmental attitudes and pro-environmental action (as measured by organization membership) is an interesting finding. When pro-environmental attitudes have become mainstream, further research should address willingness to actively support and take part in a diversity of forms of action. Another suggestion for future research is to investigate and delineate heterogeneous environmental orientations (cf. Skogen, 1999).

\section{Gender}

The findings in this study do not support the picture outlined in the introduction, i.e. that girls have a stronger environmental concern than boys, but that boys dominate in the environmental organizations. We found that there were as many boys as girls with a strong environmental concern, but that girls were a majority among organization members.

How can we explain this equality in environmental concern? One explanation is of a methodological nature: we have focused on those who have strong environmental concern. If we compare mean scores, girls do score higher, due to a larger dispersion of the boys' evaluation of the items. The equal proportions of boys and girls with strong environmental concern may also be due to boys' stronger concern for the large carnivores. If we exclude concern for the carnivores from the measure of pro-environmental attitudes, we find more girls than boys with strong environmental concern. If the fascination for large carnivores reflects a masculine orientation not specifically related to environmentalism, this may be said to weaken the finding of gender equality. On the other hand, the girls' higher mean score on the fighting pollution variable might reflect an equally gender-specific risk aversion. Since we wanted to retain items in the sum score variable that caught a diversity of environmental issues, we considered concern for the large carnivores just as relevant as a measure of environmental orientation as fear of pollution.

In review articles on studies from the USA, Mohai (1992) and Davidson \& Freudenburg (1996) concluded that women were more concerned about environmental problems than men when local issues and nuclear and technological risks were at stake. Differences tended to be more modest when broader patterns of environmental concern were measured. To explain these gender differences, Davidson \& Freudenburg (1996) emphasized women's stronger concern for safety and their tendency towards distrust in institutions of power. Both themes relate to women's orientation towards family and care, as opposed to men's orientation towards work and other arenas of power. Such a line of reasoning is quite common in the literature, and on this background our results may indicate that we are now witnessing shifting orientations among young men and women-which probably reflect increased gender equality in future expectations for work and family life.

How should we understand the girls' domination among organization members? The predominance of girls in NU might reflect that Nordic women are generally more involved in political issues than women in other Western 
countries. Or it might reflect some more widespread changes in the traditional gap between men's and women's political participation. Traditionally, women have been less interested in politics than men (Aardal, 1990; Conover, 1994). However, during recent decades there have been dramatic changes in political participation in the Western world. The gender gap in willingness to use the right to vote has more or less disappeared; educated women are as interested in politics as men, and the stereotype of the Christian and conservative female voter is no longer valid (Walker, 1994). Norwegian studies support this picture. Since the 1960s more young men than young women (below 30) have voted conservative (Listhaug \& Huseby, 1995). In the 1997 parliamentary election in Norway, a higher percentage of young women voted than young men. In a study of gender differences in voting behaviour in the Nordic countries, Oskarson (1995, p. 78) found gender differences to be greater among voters younger than 45 . Young women were found to cast their votes to the left to a higher degree than young men, while the opposite held for those over 45 .

There have also been changes in organizational activity. The traditional women's organizations are losing members and women are entering organizations previously dominated by men. The pattern of organizational membership among young women (below 40) is more similar to that of men than to that older women (above 50) (Selle \& Øymyr, 1995). In a national survey of Norwegian youth, $5 \%$ of the girls and $7 \%$ of the boys were members of political youth organizations (Øia, 1995).

The rise in women's educational aspirations is one factor behind these changes. Another factor is the expansion of the public sector, which has provided employment opportunities to a steadily growing proportion of the female workforce, and thus contributed to a fundamental shift in the socioeconomic position of women. Changes in patterns of political activity among women may be seen as a background for the willingness of young girls to participate in political organizations. This may even pertain to environmental organizations in particular, as these organizations embody values that appeal to women and allow them to express these values in a political context.

\section{Summary and Conclusion}

Young people's propensity to have a strong environmental concern and their willingness to join an environmental organization was related to the amount of cultural capital they possessed, even when controlling for class background. We suggest that these findings may be interpreted in the light of two forms of cultural domination. A strong environmental concern as well as organization membership appears to fit well within a dominant abstraction-oriented culture, but less well within a production-oriented culture. And further, a relatively high amount of cultural capital (compared to economic capital) is probably frequently accompanied by alternative values and alternative interpretations of the good life'. Such orientations appear to converge with the ideological basis of the environmental movement and other new social movements. This has been studied earlier focusing on the new middle class, but amount of cultural capital might be an important differentiating axis in other classes as well.

Political orientations were differently related to pro-environmental attitudes and pro-environmental action. A conservative political orientation corresponded with a strong environmental concern, whereas the environmental 
organization members displayed a radical leftist orientation. We suggest that environmental concern has now become integrated in a conventional political orientation among young people, while organization membership still entails subscription to a more clear-cut ideological package. If pro-environmental attitudes have become politically mainstream, further research should focus on willingness to engage in different types of action.

The results do not fit the picture outlined in the introduction regarding gender differences, where boys were anticipated to be less concerned, but more prone to join organizations. We found that as many boys as girls had a strong environmental concern, but that girls were a majority among the organization members. A general increase in aspirations regarding education and work is one factor behind growing political involvement among women. Changes in women's level of political activity probably underlay young girls' willingness to join political organizations generally, and environmental organizations especially.

\section{Acknowledgement}

This research was funded by the Norwegian Research Council.

\section{Notes}

[1] Some studies have also shown that young adults are more concerned about the environment than older adults (van Liere \& Dunlap, 1980; Granzin \& Olsen, 1991).

[2] In a study focusing on ideology, strategy and willingness to take action in environmental organizations in Norway, Jahn (1996) labelled NNV a traditional environmental organization and NU a movement organization (that is, a social movement organization).

[3] There is some discrepancy here, however. Lyons \& Breakwell (1994), among others, found no gender differences in environmental attitudes among British youth. But the overall impression is that there is a gender difference, with girls being more concerned about the environment.

[4] Particularly being critical of economic growth in combination with endorsement of the 'New Ecological Paradigm' (Dunlap et al., 1992).

[5] At the time of the data collection, unemployment had been a central political issue for many years, due to high unemployment rates at the beginning of the 1990s.

[6] Not all the differences between the two closest steps on the ranking were significant.

[7] A table is not presented here, since its interpretation would necessitate knowledge of Norwegian TV programmes from 1996.

[8] In a 1992 national survey, 3.8\% were members (ages 13-19) (Skogen, 1996b) and in 19942.9\% were members of an environmental organization (ages 14-21) (Skogen, 1996a).

[9] Examples here could be public-sector workers such as kindergarten assistants and assistant nurses.

[10] Bellona is not a democratic organization, but a foundation started by activists with a background in NU. It resembles Greenpeace in many respects, and was formed when Greenpeace largely disqualified itself in Norway due to extreme positions taken on the whaling and sealing issues.

\section{References}

AARDAL, B. (1993) De unges valg: protest eller apati? Tidsskrift for Sanfunnsforskning, 34, pp. 459-477. AXELROD, L. \& LeHMAN, D. (1993) Responding to environmental concerns: what factors guide individual action?, Environmental Psychology, 13, pp. 149-159.

BECK. U. (1992) Risk society: Towards a New Modernity (London, Sage).

Bjørklund, T. \& HelleviK, O. (1988) De grønne stridsspørsmål i norsk politikk, Politica, 20, pp. 414-431.

Bourdieu, P. (1984) Distinction. A Social Critique of the Judgement of Taste (Routledge, London). 
Conover, P.J. (1994) Feminism and the gender gap, in: M. Githen, P. NorRis \& J. Lovenduski (Eds) Different Roles, Different Voices (New York, Harper Collins).

DAVIDSON, D.J, \& FReudenburG, W.R (1996) Gender and environmental risk concern, Environment and Behavior, 28, pp. 302-339.

Douglas, M. (1992) Risk and Blame: Essays in Cultural Theory (New York, Routledge).

Douglas, M. \& Wildavsky, A. (1983) Risk and Culture. An Essay on the Selection of Technological and Environmental Dangers (Berkeley, CA, University of California Press).

Dunlap, R., van Liere, K.D., Mertig, A., Catton, W.R. \& Howell, R. (1992) Measuring endorsement of an ecological worldview: a revised NEP scale. Paper presented at the annual meeting of the Rural Sociology Society, Pennsylvania.

Eckersley, R. (1989) Green politics and the new class: selfishness or virtue?, Political Studies, 2, pp. 205-223.

EdEr, K. (1993) The New Politics of Class. Social Movements and Cultural Dynamics in Advanced Societies (London, Sage).

EDER, K. (1996) The Social Construction of Nature (London, Sage).

Furlong, A. \& Cartmel, F. (1997) Young People and Social Change. Individualisation and Risk in Late Modernity (Buckingham, Open University Press).

GIDDEnS, A. (1991) Modernity and Self-Identity: Self and Society in the Late Modern Age (Cambridge, Polity Press).

GRANZIN, K.L. \& Olsen, J.E. (1991) Characterizing participants in activities protecting the environment: a focus on donating, recycling, and conservation behaviors, Journal of Public Policy $\mathcal{E}$ Marketing, 10(2), pp. 1-27.

GRAumanN, C.F. \& KRUSE, L. (1990) The environment: social construction and psychological problems, in: H.T. Himmelweit \& G. Gaskell (Eds) Societal Psychology (London, Sage).

Hegna, K. (1996) Koss har me det? Rapport 1/96 (Oslo, Ungforsk).

INTERNATIONAL LABOUR ORgANiZATION (1990) International Standard of Classification of OccupationISCO 88.

JAHn, D. (1996) The Colors of the Green Rainbow: Ideology, Strategy and Action of Members of Environmental Organisations in Norway. Notat 9643 (Bergen, LOS-senter).

KowAleVsKI, D. (1994) Environmental attitudes in town and country: a community survey, Environmental Politics, 3(2), pp. 295-311.

KRIESI, H. (1989) New social movements and the new class in the Netherlands, American Journal of Peasant Studies, 20, pp. 389-419.

Listhaug, O. \& Huseby, H. (1995) Valgatferd blant kvinner og menn: 1957-1993, in: N. RAAum (Ed.) Kjønn og politikk (Oslo, Tano).

LYONS, E. \& BREAKWELL, G.M. (1994) Factors predicting environmental concern-and indifference in 13- to 16-year-olds, Environment and Behaviour, 26, pp. 223-238.

Macnaghten, M. \& Urry, J. (1998) Contested Natures (London, Sage).

McStay J. \& Dunlap, R.E. (1983) Male-female differences in concern for environmental quality, International Journal of Women's Studies, 6, pp. 291-301.

Mitchell, R.C. (1979) Silent spring/solid majorities, Public Opinion, 55, pp. 1-20.

Mohal, P. (1992) Men, women, and the environment: an examination of the gender gap in environmental concern and activism, Societies and Natural Resources, 5, pp. 1-9.

NÆSS, A. (1973) The shallow and the deep, long-range ecology movement: a summary, Inquiry, 16, pp. 95-100.

OsKarsson, M. (1995) Gender gaps in Nordic voting behaviour, in: L. Karvonen \& P. SELLE (Eds) Women in Nordic Politics (Aldershot, Dartmouth).

Pedersen, W. (1996) Working-class boys at the margins: ethnic prejudice, cultural capital, and gender, Acta Sociologica, 39(3), pp. 257-279.

Rosengren, K.E. (1994) Media Effects and Beyond. Cultural Socialization and Lifestyles (London, Routledge).

Scott, A. (1990) Ideology and the New Social Movements (London, Unwin Hyman).

ScotT, D. \& WillitTs, F. (1994) Environmental attitudes and behavior: a Pennsylvania survey, Environment and Behavior, 26, pp. 239-260.

SEIPPEL, Ø. (1995) Fra natur til handling. En empirisk analyse av forholdet mellom natursyn, forbruk og politisk atferd (Oslo, Alternativ framtid).

SElle, P. \& ØYMYR, B. (1995) Frivillige organisering og demokrati. Det frivillige organisasjonsamfunnet endrar seg 1940-1990 (Oslo, Samlaget).

SHAPIRO, R.Y. \& MAJAHAN, H. (1986) Gender differences in political preferences, Public Opinion Quarterly, 50, pp. 42-61. 
SKogen, K. (1996a) De skal arve jorden. Ungdom og miljøvern i 90-årene, report 3/96 (Oslo, NOVANorwegian social research).

SKOGEN, K. (1996b) Young environmentalists: post-modern identities or middle-class culture, Sociological Review, 44(3), pp. 452-473.

SKogen, K. (1998) A touch of class: the persistence of class cultures among Norwegian youth, Young-Nordic Journal of Youth Research, 6(2), pp. 15-37.

SKOGEN, K. (1999) Another look at culture and nature: how culture patterns influence environmental orientation among Norwegian youth, Acta Sociologica.

SteEL, B. (1996) Thinking globally and acting locally? Environmental attitudes, behavior and activism, Journal of Environmental Management, 47, pp. 27-36.

Stern, P., Dietz, T., Kalof, L. \& Guagnano, G. (1995) Values, beliefs and pro-environmental actions: attitude formation toward emergent attitude objects, Journal of Applied Social Psychology, 25, pp. 1611-1636.

Szagun, G. \& Pavlov, V. (1995) Environmental awareness: a comparative study of German and Russian adolescents, Youth \& Society, 27, pp. 93-112.

VAAGE, O.F. (1997) Norsk mediebarometer 1996 (Oslo, Statistics Norway).

VAN Liere, K.O. \& DunlaP, R.E. (1980) The social base of environmental concern, Public Opinion Quarterly, 44, pp. 181-197.

WALKER, N.J. (1994) What we know about women voters in Britain, France and West Germany, in: M. Githen, P. NorRis \& J. Lovenduski (Eds) Different Roles, Different Voices (New York, Harper Collins).

WALL, G. (1995) Barriers to individual environmental action: the influence of attitudes and social experiences, The Canadian Review of Sociology and Anthropology, 32, pp. 465-489.

Weiss, K., Isermann, K., Oswald, H. \& Kuhn, H.P. (1998) Parental influences on political attitudes of adolescents in eastern Germany. Paper presented at the biennial meeting of The European Association for Research on Adolescence, Budapest.

Wright, E.O. (1997) Class Counts (London, Polity Press).

ØIA, T. (1995) Apolitisk ungdom? Sjølbergingsgenerasjonen og politiske verdier (Oslo, Cappelen akademisk forlag). 